\title{
Den Pollen entflieh(g)en
}

\section{Mit gezielter Planung lassen sich schlimmsten Wochen des Jahres zu den schönsten machen}

W enn die Pollen wieder fliegen, denken viele Heuschnupfengeplagte nur noch an Flucht. Das erfordert allerdings etwas Planung: „Man muß zunächst einmal wissen, welche Pollen für die eigenen Beschwerden verantwortlich sind", erklärt Sabine Nöthlich, Pressesprecherin der Techniker Krankenkasse.

„Diesen Allergenen kann man dann gezielt ausweichen." Denn während in Mitteleuropa im Juni und Juli die Gräser in voller Blüte stehen, ist Spanien schon von diesen Pollen frei. Für Birkenpollenallergiker sind dagegen die ausgedehnten Birkenwälder Nord- und Osteuropas keine gute Wahl - sie werden dort von Ende April bis Anfang Juni kaum Erholung finden.

„Sichere Orte für Heuschnupfengeplagte finden sich zum Beispiel an der Küste," rät K.-Ch. Bergmann, leitender Arzt der Allergie- und Asthma-Klinik in Bad Lippspringe. Der Pollengehalt auf Inseln und an der Küste ist allerdings von der Windrichtung abhängig: Wind von See trägt kaum Pollen mit sich, bei Landwind können große Pollenwolken vom Festland herangeweht werden. Bergmann: „Es gilt: Je weiter weg vom Land, desto besser. Seereisen bieten fast hundertprozentige Sicherheit."

Auch das Hochgebirge sei empfehlenswert. Auf einer Höhe von über 1500 Metern ist die Pollenbelastung deutlich geringer und vor allem kürzer. Ab Ende Juni sind die Alpen in der Regel pollenfrei.

Auch Pflanzen, die in Deutschland gar nicht anzutreffen sind, können allergen wirken. Ein Beispiel ist das Glaskraut, das vor allem im Mittelmeerraum und an der Atlantikküste wächst. Wer auf Eschenpollen allergisch reagiert, sollte Regionen meiden, in denen Olivenbäume wachsen. Sie haben Pollen, die denen der Eschen sehr ähnlich sind. Für Beifußpollenallergiker gilt dasselbe beim Kreuzkraut, einer aus Nordamerika eingeschleppten Unkrautpflanze. Auf anderen Kontinenten wachsen Pflanzen, die hierzulande unbekannt sind und deshalb auch kaum allergen wirken können. Aber: Bei längeren Aufenthalten kann es zu einer Sensibilisierung kommen. Und bei einem erneuten Besuch zeigt sich die unangenehme Wirkung mit Schnupfennase und tränenden Augen. m Sommer 1996 nahm 3M Medica das besonders für Insektengift-Allergiker erforderliche Adrenalin $\mathrm{Me}$ dihaler Dosieraerosol vom Markt. Begründet wurde dies mit der FCKWHalon-Verbotsordnung. Bis vor kurzem konnte das Präparat z. B. noch aus der Schweiz oder aus England auf Einzelanforderung importiert werden. Inzwischen wurde es weltweit aus dem Handel gezogen.

Von den verfügbaren Injektionsbestecken mit Adrenalin bewerteten wir (= Arznei-Telegramm, Anm. d. Red.) 1996 nur den teuren Fastjekt (128,33 DM) als für den Laien tauglich (Arznei-Telegramm 7 (1996), 70). Immer wieder wird jedoch nach einem einfacher handhabbaren Dosieraerosol gefragt.

Ein ebenfalls FCKW-haltiges Spray mit Adrenalin kann aus den USA importiert werden: Das als Asthmamittel

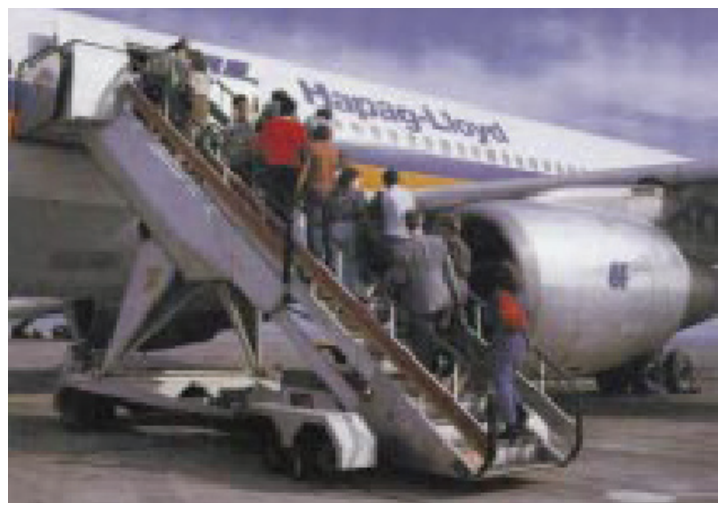

Näheres zum allergiefreien Urlaub gibt es im Internet: Unter http:// www.cat.at/pollen/ ist detailliert aufgeführt, wann Bäume und Gräser in Europa blühen. Weitere Informationen zum Thema Allergien und interessante Links bietet die Techniker Krankenkasse unter http://www.tk-online.de.

Quelle: ots.

\section{Straftat bei Verstoß gegen FCKW-Halon-Verbotsordnung}

\author{
Import Epinephrin-haltiger Dosieraerosole \\ jedoch im Einzelfall gerechtfertigt
}

angebotene Primatene Mist Complete der Firma Whitehall (Achtung: Packung enthält keine Gebrauchsinformation), Apothekenabgabepreis etwa 84,- DM.

Das Bundesinstitut für Arzneimittel und Medizinprodukte hält den Import Epinephrin-haltiger Dosieraerosole in Einzelfällen für gerechtfertigt, wenn der Arzt dieses als für die Notfallbehandlung unverzichtbar erachtet (BfArM: Schreiben vom 10. Dez. 1997 und 28. Mai 1998). „Um sich nicht dem Vorwurf eines Verstoßes gegen die FCKW-Halon-Verbotsordnung (=Straftat!) auszusetzen, muß der verordnende Arzt das Fehlen therapeutischer Alternativen darlegen können (Notstandsregelung § 34 StGB)“ (Ministerium für Arbeit, Gesundheit und Soziales, NRW, Schreiben vom 20. Mai 1998).

Quelle: Arznei-Telegramm 1998; Ausgabe 6: 59. 